\title{
Influence of an endophytic fungus on host plant selection by a polyphagous moth via volatile spectrum changes
}

\author{
Mustapha F. A. Jallow • Dereje Dugassa-Gobena • \\ Stefan Vidal
}

Received: 2 October 2007/ Accepted: 14 February 2008/Published online: 5 March 2008

(C) The Author(s) 2008

\begin{abstract}
Recently the role of micro-organisms as mediators of plant-herbivore interactions has been increasingly acknowledged in ecological research. We investigated the interaction between an unspecialized root fungal endophyte (Acremonium strictum) and the polyphagous moth Helicoverpa armigera (Hübner) (Lepidoptera: Noctuidae), in greenhouse and laboratory bioassays. Specifically we examined in tomato (Lycopersicon esculentum Mill.) the systemic effects of the endophytic fungus on the host selection behaviour of female moths for oviposition and the volatile profiles of host plants to understand the mechanisms acting in this multi-trophic model system. Both laboratory and field strains of $H$. armigera moths oviposited more on leaves of $A$. strictum inoculated plants as compared to endophyte-free plants, both in free flight cages and in tethered moth laboratory experiments; the moth's preferences were significant between 10 and 18 days after inoculation. The analysis of volatile profiles showed strong quantitative differences between treatments. Endophyte inoculated plants emitted diverse terpenes and sesquiterpenes at significantly lower amounts as compared to endophyte free-plants, except for $\alpha$-terpinene, which did not differ between the treatments, and trans- $\beta$ -
\end{abstract}

Handling Editor: Walter Carson.

M. F. A. Jallow · D. Dugassa-Gobena · S. Vidal $(\bowtie)$

Department of Crop Sciences, Georg-August-University,

Entomological Section, Grisebachstr. 6, 37077 Gottingen,

Germany

e-mail: svidal@gwdg.de

Present Address:

M. F. A. Jallow

Department of Entomology, The Ohio State University

(OARDC), 1680 Madison Avenue, Wooster,

OH 44691-4096, USA caryophyllene, which was emitted in significantly higher amounts on inoculated plants. $\beta$-Thujene and $\alpha$-phellandrene accounted for 73.3 and $12.0 \%$ of total amounts of volatiles emitted from endophyte-free and inoculated plants, respectively. Our findings demonstrate that A. strictum is able to systemically influence the host selection of $H$. armigera moths for oviposition; conceivably mediated by the induced changes in volatile emissions (and probably additional biochemical parameters of the host plants, which have not been analysed so far). We argue for a more detailed assessment of micro-organisms invisibly colonizing plants, when studying plant-herbivore or multitrophic interactions.

Keywords Fungal endophytes - Acremonium strictum . Helicoverpa armigera . Ovipositional preference . Plant volatiles

\section{Introduction}

Endophytic fungi, which live within host plant tissues without causing any visible symptoms of disease (Wilson 1995) are known to occur in almost all higher plants (Azevedo et al. 2000), and are important mediators of plant-herbivore interactions (Rajagopal and Suryanarayanan 2000; Omacini et al. 2001; Miller et al. 2002; Meister et al. 2006). They are generally viewed as mutualists; by receiving nutrition and protection from their host plants, the endophytes enhance resistance of the host plant against insect herbivores or pathogens (Clay 1990; Breen 1994). The mechanisms underlying anti-herbivore properties of endophytic fungi are attributed mainly to the production of various alkaloid-based defensive compounds in the plant tissue (Clay and Holah 1999; Faeth 2002) or through 
alteration of plant nutritional quality (e.g., phytosterols) (Bernays 1993). However, other cues, such as plant volatiles or secondary plant metabolites may influence the growth of the fungus within the plant tissue and may contribute to behavioural changes of herbivorous insects feeding on endophyte associated host plants.

Host selection by phytophagous insects involves a linked sequence of behaviours and discrimination events (Miller and Strickler 1984). Chemoreception pre-alighting cues (plant volatiles), post-alighting cues (leaf surface chemistry), and mechanoreceptor cues (leaf surface texture) may be involved in discrimination between species of plants, between individuals of the same species, and in the selection of a particular oviposition site within a plant (Bernays and Chapman 1994; Renwick and Chew 1994).

Several studies demonstrated that most plant species respond to feeding by herbivores with a blend of de novo synthesized volatiles, released by plants only when attacked by herbivores (Takabayashi et al. 1995; Turlings et al. 1990, 1998). These herbivore-induced plant volatiles also play a major role in attracting specialized parasitoids, which use these volatiles as cues when searching for their host (DeMoraes et al. 2001; Faeth and Bultman 2002). Similarly, plant pathogens may induce local or systemic emissions of volatiles or non-volatile secondary metabolites that insects may exploit for locating or discriminating between host plants (Barbosa et al. 1991; Moran 1998; Friedli and Bacher 2001; Cardoza et al. 2002, 2003; Kruess 2002; Ako et al. 2003; Huang et al. 2005).

The idea that endophytic fungi, which live asymptomatically within host plant tissues, could indirectly influence host location and oviposition behaviour of insect herbivores in a similar manner to plant pathogens, has been tested in only a few cases. So far, most research has focused on the seed-transmitted clavicipitaceous fungal endophytes of grasses that are known to produce alkaloidbased defensive compounds (Wilson and Faeth 2001; Yue et al. 2001). Among the least studied taxa of plant-associated fungal endophytes are the unspecialized, widespread soil-borne fungal endophytes belonging to the genus Acremonium. Species of this genus are commonly reported when investigating endophyte communities in plants (McGee et al. 1991; Fisher et al. 1992; Colllado et al. 1999; Kumaresan and Suryanarayanan 2001; Wicklow et al. 2005). Unlike the clavicipitaceous fungal endophytes of grasses, these endophytes are transmitted horizontally by spores (Gams 1991), are predominantly restricted to the root systems of host plants (Schulz et al. 1993), show no symptoms of infection (Bargmann and Schönbeck 1992; Raps 1997), and are commonly found in studies screening for endophyte diversity (Schulz et al. 1993; Gange et al. 2007). We are not aware of any study showing that these endophytes may synthesize alkaloid substances in their host plants, which may affect the growth and development of herbivorous insects.

Firstly, we used the soil borne endophyte Acremonium strictum to test the hypothesis that an unspecialized fungal endophyte is able to interfere with the host selection and oviposition behaviour of the polyphagous moth Helicoverpa armigera (Hübner) (Lepidoptera: Noctuidae). We tested both a laboratory strain and a field population of $H$. armigera to determine whether wild moths would respond in similar fashion as laboratory-reared moths to host plants infested by A. strictum. Secondly, we analysed the volatile profile of tomato plants (Lycopersicon esculentum L.), to understand host plant signals responsible for behavioural changes in the female moths. The results of these experiments will provide information not only to the question whether endophytic fungi are important in influencing herbivore foraging behaviour, but also towards the development of improved management strategies for insect pests.

\section{Material and methods}

Plants, fungal cultivation and inoculation

Tomato seedlings (cultivar, Suso $\mathrm{RZ}^{\circledR} \mathrm{F}_{1}$ hybrid) were grown in a greenhouse. Two weeks old plants were individually transplanted into plastic pots $(20 \mathrm{~cm}$ diameter $)$ with a mixture of sand and soil (Ökohum ${ }^{\circledR}$-Rindentorfsubstrat, Type RTS; 4:1 ratio), watered regularly and fertilized once a week with liquid fertilizer (N:P:K, 20:20:20). Pre-flowering plants, approximately at the fiveleaf stage, or plants at the early flowering stage, were used for the inoculation experiments with the root endophyte. Seedlings were transplanted at specific intervals to ensure a supply of pre-flowering and flowering plants. The root endophyte, a strain of A. strictum from DSMZ-GmbH, Braunschweig, Germany, was maintained in the laboratory on $0.3 \%$ malt extract agar (Fa. Fluka). Re-isolations have been used throughout the last years to ensure viability of the fungus. For the production of spore suspension, the autoclaved malt extract $(0.3 \% \mathrm{v} / \mathrm{w})$ was inoculated with a piece of malt extract agar containing the fungus mycelia in an Erlenmeyer flask. This was kept at $28^{\circ} \mathrm{C}$ on a shaker for approximately 3 weeks to ensure fungal growth and sporulation. The spore suspension was filtered under vacuum and the spores were quantified under a microscope using a Thoma counting chamber. Thereafter the spore concentration was adjusted with tap water to $10^{6}$ spores $/ \mathrm{ml}$. Experimental plants were inoculated with $70 \mathrm{ml}$ of this spore suspension, whereas control plants received the same amount of culture filtrate of the endophyte, filtered spore free. Following the inoculation, root samples were 
collected after 6 days from six randomly selected plants of both treatments to assess endophyte infection. Specifically, we gently separated the root system of individual plants from the soil particles, cleaned them with autoclaved tap water and sterilized them with 5\% sodium hypochlorite. After a subsequent washing with deionised and autoclaved water and cutting with sterilized scissors, we sampled root segments with an approximate length of $1 \mathrm{~cm}$ and incubated these on malt-extract-agar at room temperature. After $24 \mathrm{~h}$, we recorded the growth of endophytes at the cutting edges of incubated root segments under a microscope. If at least $20 \%$ of root segments showed endophyte growth, we regarded the inoculated plants as successfully infected and ready for use in the subsequent experiments. Furthermore, we used the same technique to verify the infection of root systems of experimental plants at the end of the respective experiments. We used the same procedure to ensure that control plants were not colonized by the endophytic fungus.

Eight days following inoculation, single plant replicates of inoculated and endophyte-free plants (pre-flowering or flowering) were used in all experiments. The experiments were conducted in a greenhouse with an average day-night temperature $24 / 16^{\circ} \mathrm{C}, 65 \%$ relative humidity (r. h.) and $16 \mathrm{~h}$ day length, under supplementary light from sodium vapour lamps.

\section{Insect rearing}

Larvae of a laboratory strain of $H$. armigera were provided by the Institute for Biological Control, Darmstadt, Germany, and reared in the laboratory at $27^{\circ} \mathrm{C}, 75 \% \mathrm{r}$. h. and a photoperiod of L16:D8 on standard bean flour based artificial diet for Helicoverpa spp. (Teakle 1991). Pupae were surface sterilized in $0.2 \%$ sodium hypochlorite solution, rinsed in distilled water, sexed, and transferred into clear containers lined with filter paper for adult emergence. The adult moths hatched directly into a mating cage $(25 \mathrm{~cm}$ $\times 25 \mathrm{~cm} \times 25 \mathrm{~cm}$ ), supplied with $10 \%$ sugar solution, and held for 3 days after eclosion to allow mating and egg maturation (Jallow and Zalucki 1998). A field population of $H$. armigera derived from larvae collected during September 2002 from cotton and tomato plants at Sevilla, Southern Spain, was reared to adult stage under similar environmental conditions as the laboratory strain.

Oviposition on inoculated and endophyte-free plants

Adult females (laboratory strain) oviposition preference for either inoculated or endophyte-free pre-flowering plants was evaluated in a laboratory flight cage $(1.5 \mathrm{~m} \times 2 \mathrm{~m}$ $\times 3 \mathrm{~m}$ ) at $27^{\circ} \mathrm{C}$ and a photoperiod of L16:D8. Six inoculated and six endophyte-free plants were distributed in two rows along the length of the cage, and were placed in alternate fashion. The plants were raised to the same height and their position rotated sequentially every 2 days to minimize any effects of plant height or environmental differences within the cage on oviposition behaviour (Firempong and Zalucki 1990). Sterile cotton balls saturated with $10 \%$ honey solution in $15 \mathrm{~cm}$ plastic containers were placed at different positions in the flight cage to serve as feeding sites for the moth. Fifteen mated females were released into the flight cage at 19:00 h prior to the onset of the scotophase. Every two days between days 8 and 24 following the inoculation of plants, eggs deposited on each plant were counted, recorded, and removed with a fine brush to avoid counting them more than once. The experiment was repeated four times using new batches of moths and plants. In a second experimental set-up, we used the same experimental procedures, repeated four times; however, this time female moths were offered inoculated and endophyte-free flowering plants. In an additional experiment, we evaluated the oviposition choice of a field population of $H$. armigera for inoculated and endophytefree flowering plants in a greenhouse flight cage $(4 \mathrm{~m}$ $\times 4 \mathrm{~m} \times 4 \mathrm{~m})$ at $27^{\circ} \mathrm{C}$ and a photoperiod of L16:D8. The larger environment of the glasshouse allowed female moths to fly more freely, thereby increasing the potential to discriminate between inoculated and endophyte-free plants. The experimental procedures, repeated four times, were the same as those for laboratory moths except that 20 mated females were released, and eight inoculated and eight endophyte-free plants were placed in the cage. The data of the replicated experiments were pooled for subsequent analyses.

Post-alighting acceptance of inoculated and endophyte-free plants

We tested the post-alighting oviposition behaviour of mated females (Laboratory strain) using a modified version (Jallow and Zalucki 1995, 1996; Cunningham et al. 1998) of a technique designed by Singer (1982). Females ready to oviposit were tethered by gluing a toothpick to the thorax under carbon dioxide anaesthesia, using a non-toxic adhesive. Care was taken to ensure that all appendages (wings, legs, antennae, and abdomen) could move freely. Females were tested individually by holding the free end of the toothpick and gently placing the moth on to a leaf disc obtained from freshly gathered inoculated or endophytefree flowering plants. The leaf discs, cut from young, fully expanded leaves, were presented in rotation at $5 \mathrm{~min}$ intervals. The first leaf presented to a female was selected at random, although the order in which a host plant is presented to a female has no effect on host acceptance by female moths (Jallow and Zalucki 1995). For each female 
tested three leaf disks from the host plants representing the two treatments were used. A host was recorded as acceptable if sustained abdominal curling and extrusion of the ovipositor was observed while in contact with the leaf disc, and was recorded as rejected if a female failed to perform this behaviour within $1 \mathrm{~min}$. The females were removed from the leaf disc before egg laying, because allowing oviposition can affect the insect's response to plants tested subsequently (Singer 1982). A female consistently accepting one host and rejecting another for three exposures to each host was recorded as preferring the accepted host. The females were individually tested every 2 days, between days 8 and 24 following the inoculation of flowering plants. New batches of mated moths and leaf discs were used on each test date.

\section{Collection of plant volatiles}

Plant volatiles were collected from non-flowering tomato plants on day 12 after inoculation for $4 \mathrm{~h}$ between $10 \mathrm{pm}$ and 2 am under the greenhouse conditions described above. The aerial portion of individual plants was contained within a $70 \mathrm{~cm}$ high $\times 40 \mathrm{~cm}$ wide $\times 40 \mathrm{~cm}$ deep ethylen-tetraflorethylen (ETFE) bag. The bags were mounted on a laboratory pedestal, the opening turned down totally covering the aerial plant parts. The opening of the bag was closed around the stem basis by mounting its opposite edges between aluminium splints, and fixing with clips. Volatile trapping was started $1 \mathrm{~h}$ later, after air homogeneity in the bags was established. The bags were featured with a hole at the upper side, which was fitted with an ETFE stopper (20 mm diameter). The ETFE stopper contained two openings $(0.67 \mathrm{~mm}$ diameter $)$. Volatiles were extracted through one of the openings from the interior bag air volume using a miniature vacuum pump (DC12/16 NK Fa. Fürgut, Germany), fixed to a volatile trapping device (Prec. Charcoal filter (1.5 mg) Fa. Brechbuehler AG, Switzerland) mounted between the bag and the pump at the inlet part of the pump. The outlet of the pump was connected with the inside of the bags by the alternative opening to maintain a constant air circulation. The air circulation rate of the pump was kept constant by adjusting it to a power supplier (PS-302 A, Fa. Conrad Electronic, Germany) at 9 volt. Volatile trapping was replicated four times using four different plants. At the end of each trapping period, the enclosed plant parts within the bags were harvested and their wet weight was determined, to be used for computing the amounts of volatiles.

Analysis of volatiles

Plant volatiles were eluted from absorbent filters with $145 \mu \mathrm{l}$ of dichloromethane and methanol $(2: 1 ; \mathrm{v} / \mathrm{v}) ; 5 \mu \mathrm{l}$
(0.001 nmol) of camphor was added as an internal standard. One micro litre aliquots of the volatile extract were analysed by capillary GC (Shimadzu $14 \mathrm{~A}$ ) equipped with a fused silica column (BP5; $30 \mathrm{~m} 0.32 \mathrm{~mm} 0.25 \mu \mathrm{m})$ and a flame ionization detector. Injections were in a splitless mode for $0.5 \mathrm{~min}$ with the injector temperature at $280^{\circ} \mathrm{C}$, and a detector temperature at $300^{\circ} \mathrm{C}$. Following injection, column temperature was held at $40^{\circ} \mathrm{C}$ for $3 \mathrm{~min}$, then increased at $10^{\circ} \mathrm{C}$ per min to $280^{\circ} \mathrm{C}$, and was held at that temperature for $10 \mathrm{~min}$. Helium was used as a carrier gas at a linear velocity of $30 \mathrm{~cm} \mathrm{~s}^{-1}$. The amount of volatile compound per plant was calculated using the individual peak areas for each compound, peak area of the internal standards and the wet weight of the respective plants. To correct for potential differences between aboveground plant biomass, we used wet weights of the plants sampled at the end of the experiment to test for differences between controls and endophyte-inoculated plants. Control plants weighed on average $80.94( \pm 0.54) \mathrm{g}$, whereas the inoculated plants weighed $81.32( \pm 0.46) \mathrm{g} \quad\left(\mathrm{F}_{(1,5)}=0.31\right.$; $P=0.602)$.

Furthermore, aliquots of the samples were analysed with GC-MS (quadrupol mass spectrometry Finnigan MAT 8230 coupled with the gas chromatography (Varian 3400) to identify the detected peaks. The detected volatiles were tentatively identified by comparing the sample spectral data with the spectral data from the National Institute of Standards and Technology (NIST 1995) database.

\section{Statistical analysis}

The mean percentage of the total number of eggs laid per day on inoculated and endophyte-free plants on each sampled day was analysed by a univariate repeated measures ANOVA. We used the percentage of times that a leaf disc was accepted by tethered females to derive a rank order of preference for the inoculated and endophyte-free plants (Jallow and Zalucki 1996). This was computed as $A \times 100 / N_{\text {max }}$, where $A$ is the number of times a plant was accepted, and $N_{\text {max }}$ the number of times a plant was tested. A Mann-Whitney $U$-test was applied to compare the quantity of volatile compounds released between treatments. We used SYSTAT 12 (2007) for all statistical analyses.

\section{Results}

Infection of roots with endophytes

We regarded endophyte infection of the inoculated plants successful, if at least $20 \%$ of root pieces placed in the agar plates showed outgrowth of the fungus. However, this 
method for assessing the endophyte infection does not allow quantifying the actual growth of the fungus within plant root tissues. We found all plants, inoculated by Acremonium strictum, to have been successfully colonized by the endophyte, whereas no control plants showed any A. strictum infections. Thus, we regarded all experimental endophyte-treated plants as belonging to this treatment.

Oviposition on inoculated and endophyte-free plants

Irrespective of the growth stages of the tomato plants tested, adult moths (laboratory strain) preferred to oviposit on inoculated as compared to endophyte-free plants. Significantly, more eggs were laid on inoculated pre-flowering plants as compared to endophyte-free plants (RM-Anova; $\mathrm{F}_{1,6}=884.8 ; P<0.001$; Table 1 and Fig. 1a). Inoculated flowering plants also received significantly more eggs as compared to endophyte-free plants at all sampling dates

Table 1 Number of Helicoverpa armigera eggs ( $N=4$ plants/ treatment; mean $\pm \mathrm{SD}$ ) removed between days 8 and 24 after inoculation on control and endophyte tomato plants

\begin{tabular}{|c|c|c|c|}
\hline \multirow[t]{2}{*}{ Experiment } & \multirow{2}{*}{$\begin{array}{l}\text { Days after } \\
\text { inoculation }\end{array}$} & \multicolumn{2}{|c|}{ Number of eggs on } \\
\hline & & Control plants & Endophyte plants \\
\hline \multirow{9}{*}{$\begin{array}{l}\text { Lab strain } \\
\quad \text { Preflowering }\end{array}$} & 8 & $72.8 \pm 13.7$ & $77.8 \pm 23.6$ \\
\hline & 10 & $58.8 \pm 22.5$ & $111.3 \pm 15.1$ \\
\hline & 12 & $32.8 \pm 5.6$ & $83.3 \pm 14.8$ \\
\hline & 14 & $25.5 \pm 5.6$ & $96.5 \pm 26.0$ \\
\hline & 16 & $30.3 \pm 7.0$ & $108.0 \pm 9.9$ \\
\hline & 18 & $43.3 \pm 14.9$ & $83.5 \pm 11.3$ \\
\hline & 20 & $48.0 \pm 14.1$ & $61.0 \pm 11.4$ \\
\hline & 22 & $22.3 \pm 8.3$ & $45.1 \pm 11.0$ \\
\hline & 24 & $27.8 \pm 11.8$ & $44.8 \pm 6.1$ \\
\hline \multirow[t]{9}{*}{ Flowering } & 8 & $90.5 \pm 7.4$ & $129.3 \pm 24.0$ \\
\hline & 10 & $45.0 \pm 5.9$ & $103.3 \pm 7.1$ \\
\hline & 12 & $63.3 \pm 5.2$ & $102.8 \pm 13.8$ \\
\hline & 14 & $27.3 \pm 9.4$ & $78.3 \pm 21.7$ \\
\hline & 16 & $24.8 \pm 12.3$ & $108.8 \pm 26.4$ \\
\hline & 18 & $52.3 \pm 20.7$ & $89.3 \pm 16.9$ \\
\hline & 20 & $52.8 \pm 15.1$ & $71.8 \pm 16.4$ \\
\hline & 22 & $45.8 \pm 3.4$ & $63.8 \pm 14.4$ \\
\hline & 24 & $64.5 \pm 27.0$ & $67.0 \pm 16.3$ \\
\hline \multirow{9}{*}{$\begin{array}{l}\text { Field strain } \\
\text { Flowering }\end{array}$} & 8 & $120.0 \pm 25.8$ & $146.3 \pm 13.2$ \\
\hline & 10 & $70.5 \pm 15.2$ & $108.0 \pm 11.0$ \\
\hline & 12 & $52.8 \pm 15.8$ & $87.3 \pm 11.5$ \\
\hline & 14 & $46.3 \pm 11.0$ & $108.5 \pm 23.5$ \\
\hline & 16 & $47.3 \pm 18.5$ & $115.0 \pm 19.2$ \\
\hline & 18 & $50.5 \pm 13.7$ & $67.5 \pm 12.0$ \\
\hline & 20 & $91.5 \pm 31.3$ & $86.3 \pm 14.9$ \\
\hline & 22 & $72.3 \pm 18.7$ & $64.5 \pm 18.0$ \\
\hline & 24 & $64.8 \pm 6.5$ & $69.3 \pm 11.5$ \\
\hline
\end{tabular}

(RM-Anova; $\quad \mathrm{F}_{1,6}=1170.4 ; \quad P<0.001 ; \quad$ Table 1 and Fig. 1b). Similarly, moths from the field population laid significantly more eggs on inoculated flowering plants as compared to endophyte-free plants ( RM-Anova; $\mathrm{F}_{1,6}=135.9 ; P<0.001 ;$ Table 1 and Fig. 2).

Post-alighting acceptance of inoculated and endophyte-free plants

Out of the females that discriminated, $73 \%$ (89 out of 121) accepted inoculated plants. Although some fluctuations between successive test dates were observed, the positive response to inoculated plants was consistent and significant for the time between days 8 and 24 following inoculation (RM-Anova; $\mathrm{F}_{1,28}=433.2 ; P<0.001 ;$ Fig. 3 ).

Volatile emission from plants

Inoculated and endophyte-free non-flowering tomato plants generally exhibited a similar volatile profile; comprising mainly of terpenes and sesquiterpenes (Table 2). The identification of the compounds was based on an approximation approach based on the comparison of analysed spectra with the spectral data bank available from NIST. The most abundant volatiles released from both inoculated and endophyte-free plants were $\beta$-thujene $\alpha$-phellandrene, representing 73.3 and $12.04 \%$ of total volatiles emitted, respectively. Inoculated plants showed significantly $(P<0.05)$ less quantity of volatile chemicals emission as compared to endophyte-free plants, except for two compounds. Inoculated plants released significantly $(P<0.05)$ more trans- $\beta$-caryophyllene as compared to the endophytefree plants, whereas no significant differences $(P>0.05)$ were detected in the quantity of $\alpha$-terpinene released between the treatments. These differences between the volatile amounts of endophyte inoculated and control plants are not related to plant size. Endophyte inoculations had no effects on the growth of the host plant as determined by the wet weight at the end of experiment (endophytes inoculated $81.32 \pm 0.46 ; \quad$ control $80.94 \pm 0.54 \mathrm{~g}$; $\left.\mathrm{F}_{(1,5)}=0.31, P=0.602\right)$.

\section{Discussion}

The results of our study demonstrate that an unspecialized soil-borne endophytic fungus, even through a temporarily limited interaction, may play a mediating role in plantinsect interactions. This result is even more surprising taking into account that $H$. armigera is a polyphagous herbivore, known to feed on more than 200 different host plant species belonging to 47 families (Zalucki et al. 1986, 1994). Irrespective of the growth stages of the host plants, 
Fig. 1 Mean percentages $( \pm \mathrm{SD})$ of the total number of eggs oviposited by Helicoverpa armigera (laboratory strain) on (a) pre-flowering and (b) flowering Acremonium strictum inoculated and endophyte-free tomato plants $(\mathrm{dpi}=$ days past inoculation)
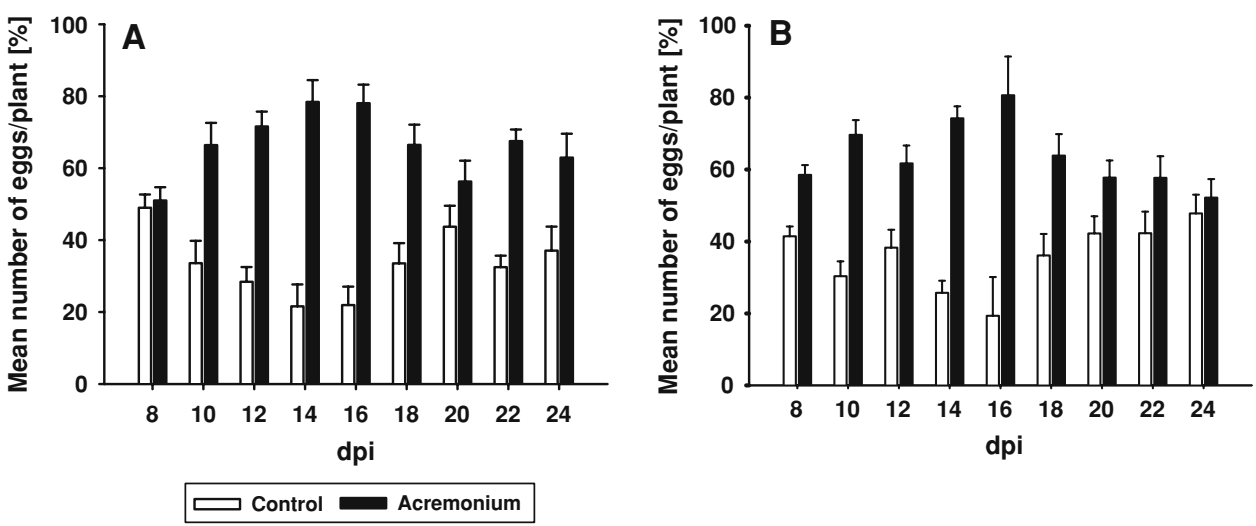

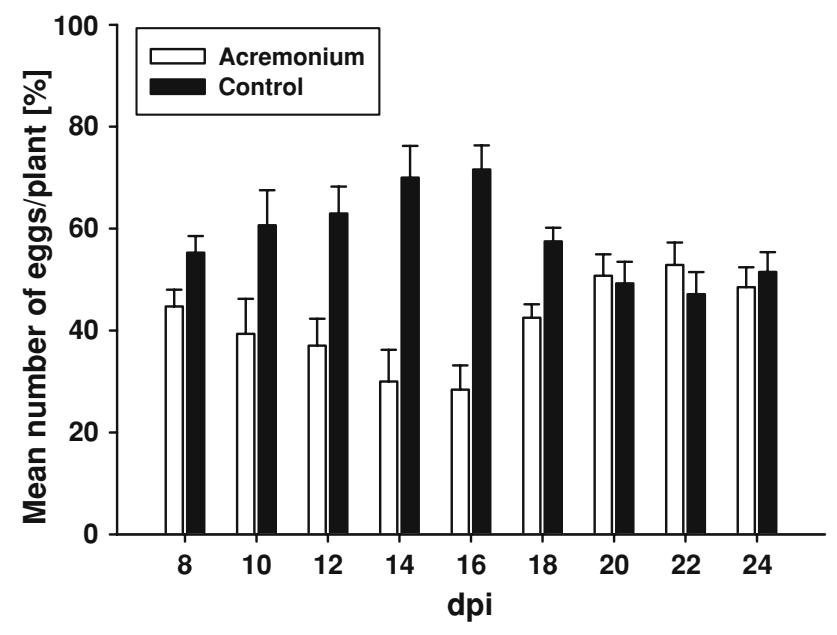

Fig. 2 Mean percentages $( \pm S D)$ of the total number of eggs oviposited by Helicoverpa armigera (field population) on Acremonium stictum inoculated and endophyte-free flowering tomato plants $($ dpi $=$ days past inoculation $)$

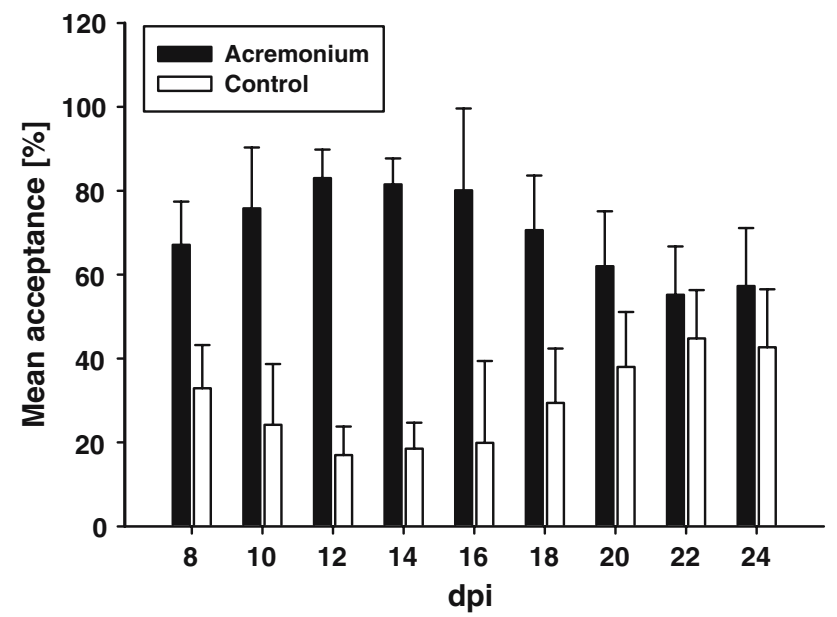

Fig. 3 Mean percentages $( \pm S D)$ of number of times tethered Helicoverpa armigera females (laboratory strain; $n=30$ ) accepted Acremonium strictum inoculated and endophyte-free flowering tomato plants. Acceptance was computed as $A \times 100 / N_{\max }$, where $A$ is the number of times a plant was accepted, and $N_{\max }$ the number of times a plant was tested (dpi $=$ days past inoculation)
Table 2 Quantity of volatile compounds emitted by Acremonium strictum inoculated and endophyte-free intact flowering tomato plants $(N=4 \text { plants/treatment; mean } \pm \mathrm{SE},(\mathrm{nmol} / \mathrm{g} / \mathrm{h}))^{\mathrm{a}}$

\begin{tabular}{lcc}
\hline Volatile compound & Endophyte-free & \multicolumn{1}{l}{ A. strictum } \\
\hline$\beta$-thujene & $6383.97 \pm 55.15$ & $3870.73 \pm 34.63^{*}$ \\
$\alpha$-phellandrene & $1107.82 \pm 18.9$ & $576.13 \pm 12.30^{*}$ \\
$\alpha$-pinene & $352.20 \pm 49.62$ & $153.20 \pm 20.94^{*}$ \\
p-cymene & $157.33 \pm 23.41$ & $90.28 \pm 16.36^{*}$ \\
$\beta$-phellandrene & $151.20 \pm 9.24$ & $135.42 \pm 8.10^{*}$ \\
m-cymene & $132.98 \pm 10.14$ & $96.48 \pm 9.87^{*}$ \\
trans- $\beta$-caryophyllene & $127.35 \pm 15.04$ & $229.58 \pm 8.39^{*}$ \\
2-carene & $121.48 \pm 1.23$ & $51.18 \pm 8.38^{*}$ \\
$\alpha$-copaene & $94.40 \pm 3.98$ & $75.23 \pm 2.94^{*}$ \\
$\alpha$-terpinene & $42.03 \pm 3.30$ & $45.85 \pm 0.55 \mathrm{~ns}$ \\
\hline
\end{tabular}

* Significant difference between endophyte-free and A. strictum inoculated plants (Mann-Whitney $U$-test; $P<0.05$ )

ns: Not significant

${ }^{\text {a }}$ Volatiles collected at day 12 following inoculation

adult females (laboratory or field strain) exhibited a significantly higher preference for endophyte-infected plants, ovipositing more eggs on these plants as compared to endophyte-free plants. The attractiveness of inoculated plants was more evident with tethered females; $73 \%$ of females tested in the post-alighting host selection bioassays accepted inoculated plants as their most preferred. Our findings that $A$. strictum may play a mediating role in the host selection behaviour of $H$. armigera are consistent with those reported by Moll and Vidal (1996) and Vidal (1996), who found similar attractiveness of tomato plants (L.esculentum) inoculated with A. strictum, for adult whiteflies (Trialeurodes vaporariorum (Westw.). Similarly, H. armigera laid significantly more eggs on cotton plants inoculated with A. strictum than on endophyte-free plants (Jallow pers. observ.). Whether preference for inoculated plants recorded in the laboratory and glasshouse actually reflects what occurs under natural conditions in the field is yet to be determined. However, that inoculated plants 
exhibit increased attractiveness for egg laying female moths from the field (this study) suggest that similar responses may exist at the field level as demonstrated in some fungal pathogen-plant-herbivore interactions (Friedli and Bacher 2001; Johnson et al. 2003).

We found the oviposition preference for endophyte plants in female moth to be significantly enhanced only for a period of 1 week at 10 days past inoculation. Thereafter this preference vanished when using flowering plants, or the field strain of $H$. armigera, or testing tethered females from 20 days onwards past inoculation. We did not quantify the colonisation of the root tissues by the endophytic fungus during the time of executing the experiments, thus we are not able to give a convincing explanation for these identical observations. We speculate that either the growth of the fungus was too slow to maintain a certain level of colonisation of the root system (dilution effect) or that the colonisation of the root tissue by the endophyte induced a systemic response. With increasing time past inoculation, the plant metabolism adjusted itself to this invading organism (wound healing effect).

Visual and chemical cues (volatile and/or leaf surface chemicals) are known to mediate the host location and oviposition behaviour of insect herbivores (Bernays and Chapman 1994; Renwick and Chew 1994). Although in our study volatiles released from inoculated and endophytefree plants were generally similar (i.e. quality), there was a difference in the quantity and relative proportion of these compounds released. Insect herbivory often causes an increase in volatile output or a quantitative change (Takabayashi et al. 1995; Turlings et al. 1990, 1998); interestingly in our system, there was a general reduction in volatile output. Insects have the ability not only to perceive but also to compare the relative quantities of compounds involved in selecting a host plant (Visser 1986). The response of insects to plant odour may depend on the presence of each component of volatiles, the presence of a specific volatile, or on the relative proportion of certain components within the blend (Visser 1986; Ramaswamy 1988). Conceivably, the alteration of plant volatiles may be a key signal used by $H$. armigera to discriminate between inoculated and endophyte-free plants. In our experiments however, we did not directly test whether host selection by female moths was caused by the difference in volatile emissions between inoculated and endophyte-free plants. Consequently, it cannot be concluded that volatiles alone were responsible for the differences in egg numbers between inoculated and endophyte-free plants. Moreover, the possibility that visual, contact chemoreception and mechanoreception cues, or other changes on the leaf surface due to the endophyte infection, might have caused the observed effects on $H$. armigera oviposition behaviour cannot be ruled out.
Only few studies have reported on the interactions between endophyte colonisation of host plants (other than the specialized grass endophytes) and insect herbivore responses. Rabin and Pacovsky (1985) found a negative correlation between mycorrhizal fungal infection of soybeans and larval development in Heliothis zea and Spodoptera frugiperda. Gange and West (1994) found a reduced growth rate of Arctica caja larvae on Plantago lanceolata when infected by mycorrhizal fungi. However, we are not aware of any studies testing for the effects of mycorrhizal colonisation of plants on the oviposition preference of female moths for these plants as compared to non-infected controls.

Plants inoculated with A. strictum exhibited an increased attractiveness for egg laying in other herbivorous insects as well, however, larvae feeding on these plants suffer from a reduction in growth rate, prolonged developmental time, suppressed moulting, and subsequently a higher mortality rate (Vidal 1996; Raps and Vidal 1998; Dugassa-Gobena et al. 2003; Jallow et al. 2003). The results reported by Rabin and Pacovsky (1985) or Gange and West (1994) fit into the pattern analysed by Gange et al. (2002). They found that plant families or species, which are strongly mycorrhizal, have lower proportions of chewing insects. Thus, Acremonium strictum acts on herbivore-plant-interactions in a similar way as mycorrhizal fungi do. This is consistent with the view of Xiao and Berch (1999) who consider A. strictum as an unusual mycorrhizal fungus.

We attribute the mechanisms underlying fungal endophyte mediation of plant-herbivore interactions to a complex of interacting factors, mediated through the interplay of metabolic processes in both the fungus and the plant following infection (Barbosa et al. 1991). Endophytic fungi can indirectly affect insect herbivores by altering plant nutritional chemistry and morphological traits (Duffey and Felton 1991; Bernays 1993), through the production of alkoloid-based defensive compounds in the plant tissues (Clay and Holah 1999), or through competition between the fungus and the herbivore for a resource supplied by their shared host plant essential for both organisms (Hendrix 1970). In our system, phytosterols (Dugassa-Gobena et al. 1998) and volatile profiles (this study) are the only plant metabolites known so far to be altered quantitatively as well as in proportional compositions in inoculated plants. However, it is unlikely that changes in egg laying behaviour of our test insect on endophyte-infected plants can be related to phytosterol composition. On the other hand, larvae feeding on infected plants have to cope with a low nutritional quality of the food ingested, which results from changes in the ratio of phytosterols to other secondary metabolites (DugassaGobena et al. 1998; Raps and Vidal 1998; Jallow et al. 
2003). So far we do not know whether the biochemical traits involved are triggered directly by the growth of the fungal endophyte, or indirectly mediated by the plant in response to the fungal infection. Our experimental settings do not allow establishing a clear relationship between volatile changes and altered oviposition behaviour of $\mathrm{He}$ licoverpa armigera females. Nevertheless, herbivoreinduced plant volatiles were reported as signals that serve predators to guide into the microhabitats of their prey (Dicke et al. 1990; Turlings et al. 1990; Takabayashi and Dicke 1994; De Moraes et al. 1998). Thus, oviposition preference of Helicoverpa moth may be an evolutionary adaptation to host plants with low amount of volatile emissions to escape egg predators or parasitoids using these volatiles as foraging cues for prey. Interestingly, the endophyte infected tomato plants produces higher amount of specific compounds, such as trans- $\beta$-caryophyllene (the only compound found with a significantly higher amount in the endophyte infected plants). This compound has been reported as a cue for entomopathogenic nematodes when locating their herbivorous larvae (Rasmann et al. 2005).

In case endophyte host plant colonisation events will repeatedly and randomly occur under field conditions throughout the growing season, the result will be a patchy or mosaic pattern of more conspicuous host plants visited by ovipositing herbivores. This phenotypic plasticity of the host plants induced by the endophytic fungus (or by several endophytic fungi) also generates a specific bouquet of volatiles which may be used by natural enemies for host location because of its uniqueness. Phenotypic plasticity contributes to the abundance and distribution of herbivores (Agrawal 2001); it would be interesting to see if, under field conditions, the endophyte infected plants suffer from less herbivory because of induced resistance or via higher natural enemy densities.

In this study we unambiguously demonstrated that an unspecialized fungal endophyte indirectly mediated the host selection and oviposition behaviour of a polyphagous moth. Consequently, endophytic fungi should be considered as an important source of variability, which needs to be taken into account when investigating plant-insect interactions.

Acknowledgements We very much appreciate the constructive comments of the handling editor and two reviewers on a previous draft of this manuscript. We are grateful to A. Mennerich for maintaining the fungal culture, A. Metje for the glasshouse work and J. M. Durán for providing field insects. The Alexander von Humboldt Foundation supported this research by a Georg Foster fellowship to MFAJ.

Open Access This article is distributed under the terms of the Creative Commons Attribution Noncommercial License which permits any noncommercial use, distribution, and reproduction in any medium, provided the original author(s) and source are credited.

\section{References}

Agrawal AA (2001) Phenotypic plasticity in the interactions and evolution of species. Science 294:321-326

Ako M, Schulthess F, Gumedzoe MYD, Cardwell KF (2003) The effect of Fusarium verticillioides on oviposition behaviour and bionomics of lepidoptera and coleopteran pests attacking the stem and cobs of maize in West Africa. Entomol Exp Appl 106:201-210

Azevedo JL, Maccheroni W Jr, Pereira JO, Araujo WL (2000) Endophytic microorganisms: a review on insect control and recent advances on tropical plants. Electron J Biotechnol 3:40-65

Barbosa P, Krischik VA, Jones CG (1991) Microbial mediation of plant-herbivore interactions. Wiley, New York USA

Bargmann C, Schönbeck F (1992) Acremonium kiliense as inducer of resistance to wilt diseases on tomatoes. J Plant Dis Plant Prot 99:266-272

Bernays EA (1993) Plant sterols and host-plant affiliations of herbivores. In: Bernays EA (ed), Insect-plant interactions, vol IV. CRC, Boca Raton, Fla, USA, pp 45-57

Bernays EA, Chapman RF (1994) Host-plant selection by phytophagous insects. Chapman \& Hall, New York, USA

Breen JP (1994) Acremonium endophyte interactions with enhanced plant resistance to insects. Annu Rev Entomol 39:401-423

Cardoza YJ, Alborn HT, Tumlinson JH (2002) In Vivo volatile emissions from peanut plants induced by simultaneous fungal infection and insect damage. J Chem Ecol 28:161-174

Cardoza YJ, Teal PEA, Tumlinson JH (2003) Effect of peanut plant fungal infection on oviposition preference by Spodoptera exigua and on host-searching behavior by Cotesia marginiventris. Environ Entomol 35:970-976

Clay K (1990) Fungal endophytes of grasses. Annu Rev Ecol Syst 21:255-297

Clay K, Holah J (1999) Fungal endophyte symbiosis and plant diversity in successional fields. Science 285:1742-1744

Collado J, Platas G, Gonzalez I, Pelaez F (1999) Geographical and seasonal influences on the distribution of fungal endophytes in Quercus ilex. New Phytol 144:525-532

Cunningham JP, Jallow MFA, Wright DJ, Zalucki MP (1998) Learning in host selection in Helicoverpa armigera (Hübner)(Lepidoptera: Noctuidae). Anim Behav 55:227-234

De Moraes CM, Lewis WJ, Pare PW, Alborn HT, Tumlinson JH (1998) Herbivore-infested plants selectively attract parasitoids. Nature 393:570-573

DeMoraes CM, Mescheer MC, Tumlinson JH (2001) Caterpillarinduced nocturnal plant volatiles repel nonspecific females. Nature 410:577-580

Dicke M, Sabelis MW, Takabayashi J, Bruin J, Posthumus MA (1990) Plant strategies of manipulating predator-prey interactions through allelochemicals: prospects for application in pest control. J Chem Ecol 16:3091-3118

Duffey SS, Felton GW (1991) Enzymatic antinutriative defenses of the tomato plants against insects. In: Hedin PA (ed), Naturally occurring pest bioregulators. American Chemical Society, Washington, DC, pp 166-197

Dugassa-Gobena D, Raps A, Vidal S (1998) Influence of fungal endophytes on allelochemicals of their host plants and the behaviour of insects. Med Fac Landbouw Univ Gent 63:333-337

Dugassa-Gobena D, Jallow MFA, Vidal S (2003) The impact of unspecialized fungal endophytes on insect-plant-interactions. Rec Res Develop Entomol 4:19-31

Faeth SH (2002) Are endophytic fungi generally plant mutualists? Oikos 98:25-36

Faeth SH, Bultman TL (2002) Endophytic fungi and interaction among host plants, herbivores, and natural enemies. In: 
Tscharntke T, Hawkins BA (eds) Multitritrophic level interactions. Cambridge University Press, UK, pp 89-123

Firempong S, Zalucki MP (1990) Host plant selection by Helicoverpa armigera (Hübner) (Lepidoptera: Noctuidae): role of certain plant attributes. Aust J Zool 37:675-683

Friedli J, Bacher S (2001) Mutualistic interaction between a weevil and a rust fungus, two parasites of the weed Cirsium arvense. Oecologia 129:571-576

Fisher PJ, Petrini O, Lappin Scott HM (1992) The distribution of some fungal and bacterial endophytes in maize (Zea mays $\mathrm{L}$ ). New Phytol 122:299-305

Gams W (1991) Cephalosporium-artige Schimmelpilze (Hyphomycetes). Fischer, Stuttgart

Gange AC, West HM (1994) Interactions between arbuscular mycorrhizal fungi and foliar-feeding insects in Plantago lanceolata L. New Phytol 128:79-87

Gange AC, Stagg PG, Ward LK (2002) Arbuscular mycorrhizal fungi affect phytophagous insect specialism. Ecol Lett 5:11-15

Gange AC, Dey S, Currie AF, Sutton BC (2007) Site- and speciesspecific differences in endophyte occurrence in two herbaceous plants. J Ecol 95:614-622

Hendrix JW (1970) Sterols in growth and reproduction of fungi. Annu Rev Phytopathol 8:111-130

Huang J, Schmelz EA, Alborn H, Engelberth J, Tumlinson JH (2005) Phytohormones mediate volatile emissions during the interaction of compatible and incompatible pathogens: the role of ethylene in Pseudomonas syringae infected tobacco. J Chem Ecol 31:439-459

Jallow MFA, Zalucki MP (1995) A technique for measuring intraspecific variation in oviposition preference in Helicoverpa armigera (Hübner) (Lepidoptera: Noctuidae). J Aust Entomol Soc 34:281-288

Jallow MFA, Zalucki MP (1996) Within- and between-population variation in host-plant preference and specificity in Australian Helicoverpa armigera (Hübner)(Lepidoptera: Noctuidae). Aust J Zool 44:503-519

Jallow MFA, Zalucki MP (1998) Effects of egg load on the hostselection of Helicoverpa armigera (Hübner) (Lepidoptera: Noctuidae). Aust J Zool 46:291-299

Jallow MFA, Dugassa-Gobena D, Vidal S (2003) Indirect interaction between an unspecialised endophytic fungus and a polyphagous moth. Basic Appl Ecol 5:183-191

Johnson SN, Douglas AE, Woodward S, Hartley SE (2003) Microbial impacts on plant-herbivore interactions: the indirect effects of a birch pathogen on a birch aphid. Oecologia 134:388-396

Kumaresan V, Suryanarayanan TS (2001) Occurrence and distribution of endophytic fungi in a mangrove community. Mycol Res 105:1388-1391

Kruess A (2002) Indirect interaction between a fungal plant pathogen and a herbivorous beetle of the weed Cirsium arvense. Oecologia 130:563-569

McGee PA, Hincksman MA, White CS (1991) Inhibition of growth of fungi isolated from plants by Acremonium strictum. Aust J Agric Res 42:1187-1193

Meister B, Krauss J, Harri SA, Schneider MV, Müller CB (2006) Fungal endosymbionts affect aphid population size by reduction of adult life span and fecundity. Basic Appl Ecol 7:244-252

Miller JR, Strickler K (1984) Finding and accepting host plants. In: Bell WJ, Cardé R (eds) Chemical ecology of insects. Chapman and Hall, London, UK, pp 127-157

Miller JD, Mackenzie S, Foto M, Adams GW, Findlay JA (2002) Needles of white spruce inoculated with rugulosin-producing endophytes contain rugulosin reducing spruce budworm growth rate. Mycol Res 106:471-479

Moll M, Vidal S (1996) Einfluss eines bodenbürtigen Endophyten, Acremonium strictum, auf das Wirtswahlverhalten und die
Entwicklung des Phloemsaugers Trialeurodes vaporariorum an Buschbohnen. Mitt Dtsch Ges allg angew Entomol 10:445-448

Moran PJ (1998). Plant-mediated interactions between insects and a fungal plant pathogen and the role of plant chemical responses to infection. Oecologia 115:523-530

Omacini M, Chaneton EJ, Ghersa CM, Müller CB (2001) Symbiotic fungal endophytes control insect host-parasite interaction webs. Nature 409:78-81

Rabin LB, Pacovsky R (1985) Reduced larva growth of two Lepidoptera (Noctuidae) on excised leaves of soybean infected with mycorrhizal fungus. J Econ Entomol 78:1358-1363

Rajagopal K, Suryanarayanan TS (2000) Isolation of endophytic fungi from leaves of neem (Azadirachta indica A. Juss). Curr Sci 78:1375-1377

Ramaswamy SB (1988) Host finding by moths: sensory modalities and behaviours. J Insect Physiol 34:235-249

Raps A (1997) Der Einfluß pilzlicher Endophyten auf die Entwicklung von Herbivoren unterschiedlicher Lebensweise an Kulturpflanzen. Ph.D. Thesis, Universität Hannover

Raps A, Vidal S (1998) Indirect effects of an unspecialized endophytic fungus on specialized plant-herbivorous insect interactions. Oecologia 114:541-547

Rasmann S, Tobias G. Köllner T G, Degenhardt J, Hiltpold I, Toepfer S, Kuhlmann U, Gershenzon J, Turlings TCJ (2005) Recruitment of entomopathogenic nematodes by insect-damaged maize roots. Nature 434:732-737

Renwick JAA, Chew FS (1994) Oviposition behaviour in lepidoptera. Annu Rev Entomol 39:377-400

Schulz B, Wanke U, Draeger S, Aust HJ (1993) Endophytes from herbaceous plants and shrubs: effectiveness of surface sterilization methods. Mycol Res 97:1447-1450

Singer MC (1982) Quantification of host preference by manipulation of oviposition behaviour in the butterfly Euphydryas editha. Oecologia 52:224-229

Takabayashi J, Dicke M, Posthumus MA (1994) Volatile herbivoreinduced terpenoids in plant-mite interactions: variation caused by biotic and abiotic factors. J Chem Ecol 20:1329-1354

Takabayashi J, Takahashi S, Dicke M, Posthumus MA (1995) Developmental stages of herbivore Pseudaletia separata affects production of herbivore-induced synomone by corn plants. J Chem Ecol 21:273-287

Teakle RE (1991) Laboratory culture of Helicoverpa spp., methods and prospects. Springer-Verlag, New York, USA

Turlings TCJ, Tumlison JH, Lewis WJ (1990) Exploitation of herbivore-induced plant odours by host-seeking parasitic wasps. Science 250:1251-1253

Turlings TCJ, Bernasconi M, Bertossa R, Bigler F, Caloz G, Dorn S (1998) The induction of volatile emission in maize by three herbivore species with different feeding habits: possible consequences for their natural enemies. Biol Control 11:122-129

Vidal S (1996) Changes in suitability of tomato for whiteflies mediated by a nonpathogenic endophytic fungus. Entomol Exp Appl 80:272-274

Visser JH (1986) Host odour perception in phytophagous insects. Annu Rev Entomol 31:121-144

Wicklow DT, Roth S, Deyrup ST, Gloer JB (2005) A protective endophyte of maize: Acremonium zeae antibiotics inhibitory to Aspergillus flavus and Fusarium verticillioides. Mycol Res 109:610-618

Wilson D (1995) Endophyte-the evolution of a term, and clarification of its use and definition. Oikos 73:274-276

Wilson D, Faeth SH (2001) Do fungal endophytes result in selection for leafminer ovipositional preference? Ecology 82:1097-1111

Xiao G, Berch SM (1999) Organic nitrogen use by salal ericoid mycorrhizal fungi from northern Vancouver Island and impacts on growth in vitro of Gaultheria shallon. Mycorrhiza 9:145-149 
Yue Q, Wang C, Gianfagna TJ, Meyer WA (2001) Volatile compounds of endophyte-free and infected tall fescue (Festuca arundinacea Schreb.). Phytochemistry 58:935-941

Zalucki MP, Daglish G, Firempong S, Twine PH (1986) The biology and ecology of Heliothis armigera (Hübner) and H. punctigera Wallengren (Lepidoptera: Noctuidae) in Australia: what do we know? Aust J Zool 34:779-814
Zalucki MP, Murray DAH, Gregg PC, Fitt GP, Twine PH, Jones C (1994) Ecology of Helicoverpa armigera (Hübner) and $H$. punctigera (Wallengren) in the inland of Australia: larval sampling and host plant relationships during winter and spring. Aust J Zool 42:329-346 